\title{
Difficulties of Solar PV Integration in Island Electrical Networks - Case Study in the French Islands
}

\author{
Gilles Notton ${ }^{1, *}$, Cyril Voyant ${ }^{2,3}$ and Jean Laurent Duchaud ${ }^{1}$ \\ ${ }^{1}$ Research centre Georges Peri, University of Corsica Pasquale Paoli, UMR CNRS 6134, 20000 Ajaccio, France \\ ${ }^{2}$ Castelluccio Hospital, Radiotherapy Unit, BP 85, 20177 Ajaccio, France, France \\ ${ }^{3}$ University of Reunion Island - PIMENT Laboratory, 15, Avenue René Cassin, BP 97715 Saint-Denis Cedex, France
}

\begin{abstract}
Integrating intermittent and non-predictable renewable energy systems in an electrical network is a difficult task and a technical challenge mainly in an island network. The technical problems occurring in small not interconnected networks is explained. The electrical energy situation of several French islands spread over the World is analysed. Various aspects are successively studied: repartition of energy means, renewable energy part in the production with a focus on the intermittent renewable part. The electricity production cost in the islands are presented and the legal and financial features for renewable energy in France are exposed. In a second part, a focus is realized on the Corsica Island situated in the Mediterranean Sea and partially connected to Italy. Successively, the energy mix, the objective of the new energy plan for 2023 and the renewable energy situation, present and future, are presented. Even if the integration of nonprogrammable renewable energy plants is more complex in small insular networks, the high cost of electricity generation in such territories encourages the introduction of wind and PV systems. The islands are good laboratories for the development of intermittent and stochastic renewable energy systems.
\end{abstract}

\section{Introduction}

In Europe, there are about 300 islands (6\% of territory) for $14 \mathrm{M}$-inhabitants, i.e. higher than the population of some European countries. More than 100.000 islands of all sizes are scattered in the World in all the latitudes and longitudes with almost $500 \mathrm{M}$-inhabitants. The total islands area is 1/6 of the Earth area.

In a first part, the electrical energy mix of the main French islands will be presented and it will highlight that fuel generators are mainly used inducing electricity production costs much higher than in inland; which has led each state to adopt specific measures to take into account these specificities.

Despite the fact that the intermittent character of the production raises more complex problems for islands than for large interconnected electrical networks, it will be shown that the part of intermittent and stochastic Renewable Energy (RE) systems in islands is more important that in mainland; it is due to the high cost of the other energy means which pushes islands to use their natural resources; but this objective can be reached only with the development of efficient prediction of the energy production, through the development of energy storage means and an optimal management of the energy flux via the utilization of smart grids.

Then, a special focus is realized on the energy situation of Corsica with the specificity to be partially connected with the Italian mainland; its electrical energy situation is based on an energy tripod: 1/3 importation, 1/3 fuel

\footnotetext{
* Corresponding author: gilles.notton@univ-corse.fr
}

and 1/3 RE with in the future a larger RE part and a reduction of the energy consumption.

\section{The main French islands}

The metropolitan France has an important number of islands and islets (about 1300) mainly situated in Bretagne and in Mediterranean Sea. Corsica represents about $90 \%$ of the island area of the metropolitan France. But the French territory spreads also from subarctic and Antarctic area to tropical and equatorial forests over the two hemispheres. The overseas territories are organized administratively in departments and communities presented in Fig. 1.

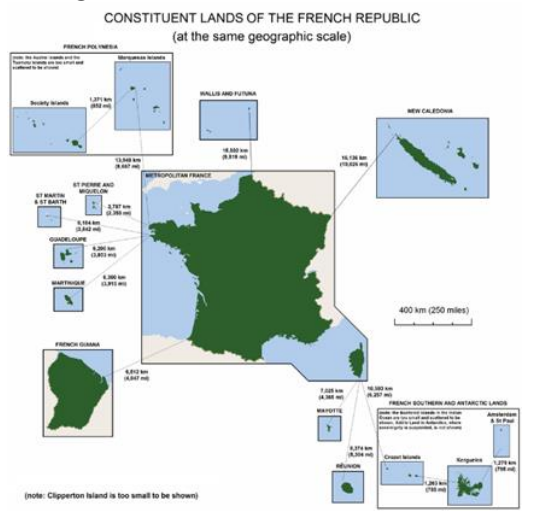

Fig. 1. French territories spread over the World (Wikipedia)

Only the main (biggest) islands are presented here (Fig 2 and Table 1). 


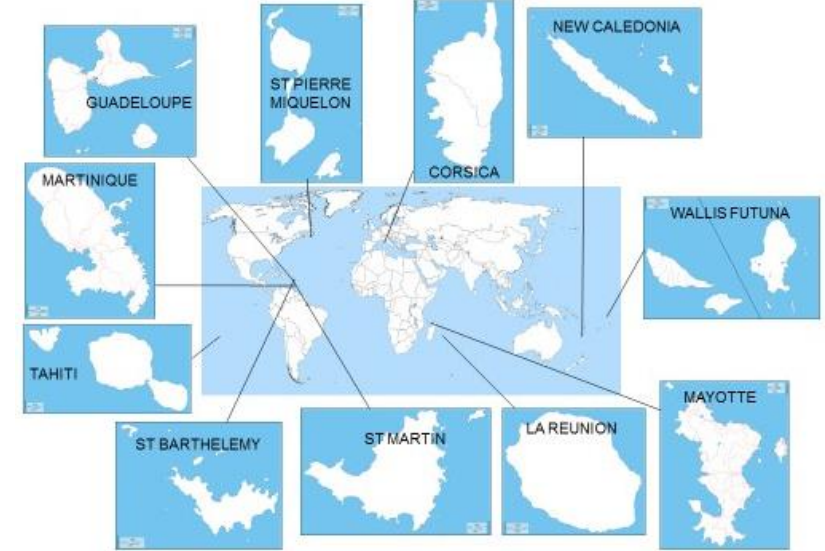

Fig. 2. Main French islands presented in this study.

Table 1. Superficies, population and density.

\begin{tabular}{ccccc}
\hline & $\begin{array}{c}\text { Inhabits } \\
(2015)\end{array}$ & $\begin{array}{c}\text { Area } \\
\left(\mathrm{km}^{2}\right)\end{array}$ & $\begin{array}{c}\text { Density } \\
\left(\mathrm{inh} / \mathrm{km}^{2}\right)\end{array}$ & Sea \\
\hline Corsica & 337796 & 8680 & 39 & Mediterranean \\
Guadeloupe & 390704 & 1628 & 240 & Atlantic \\
Martinique & 371246 & 1128 & 329 & Atlantic \\
Reunion & 842767 & 2512 & 335 & Indian ocean \\
St Barthelemy & 9417 & 21 & 448 & Atlantic \\
$\quad$ St Martin & 37630 & 53 & 710 & Atlantic \\
St Pierre \& & 6312 & 242 & 26 & Atlantic \\
Miquelon & & & & \\
French Polynesia & 275918 & 3792 & 73 & Pacific \\
(Tahiti) & 259154 & 375 & 691 & Indian ocean \\
Mayotte & 268767 & 18576 & 14 & Pacific \\
New Caledonia & 11901 & 142 & 84 & Pacific \\
Wallis \& Futuna & 119638 & 551695 & 122 & \\
France & 67186638 & & &
\end{tabular}

Thus, the size of these islands are very different from 21 $\mathrm{km}^{2}$ for Saint Martin to $18576 \mathrm{~km}^{2}$ for New Caledonia.

\section{Electrical problematic of islands}

The insular electrical systems are governed by the same electro technical rules as those that are applied in mainland networks but the absence or the limitation of an interconnection to a large network provide it some specificities recognized by the competent European and French authorities [1].

As the islands are not or only partially interconnected, the energy manager has to reach the supply/demand balance without the assistance of external production means located on neighbouring areas. Islands have a structural fragility: a short circuit in the electrical system will generate a voltage drop in all the island [2-3], the low inertia implies a high frequency variability with consequences on the voltage [2-3]; the previous problems are compounded by the large unit size of an electrical generator in comparison with the peak power in the network. The default probabilities in an insular network are very high compared with an interconnected network [3]. Voltage and frequency drops are more numerous and deeper in islands than in mainland (dozens each year) [2]. In Corsica, before the partial AC interconnection with Sardinia, more than 200 failures per year occurred on the transmission network with voltage and frequency dips (less than $46 \mathrm{~Hz}$ ) [4].
Islands have often a small population, a low and variable energy consumption (in Corsica, a minimum of $130 \mathrm{MW}$ in May and a maximum of $500 \mathrm{MW}$ in December) that prohibits the use of high rated power production means and requires the utilization of small rated power electrical plants for a better adaptation to the load and for limiting the disturbances due to the loss of a plant; few electrical systems exist with a low rated power.

An electrical unit peak power must not exceed $25 \%$ of the average power in the network [1] (in the $300 \mathrm{GW}$ European grid, the loss of a $1.3 \mathrm{GW}$ nuclear unit results in a ratio of $0.4 \%$; in a $200 \mathrm{MW}$ insular grid, the loss of a $40 \mathrm{MW}$ unit results in a ratio of $20 \%$ ). In the islands, the loss of a power unit has very negative consequences: the loss of a $1300 \mathrm{MW}$ nuclear unit on the French territory leads to a speed of the frequency variation of only 6 $\mathrm{mHz} / \mathrm{s}$, but, in Corsica, the loss of the $50 \mathrm{MW} \mathrm{DC/AC}$ conversion unit causes a variation of $2.8 \mathrm{~Hz} / \mathrm{s}$ [5].

To have an margin of power able to react rapidly to an increase/decrease of the consumption, the production group must operate at part-load (starting a new plant takes time); thus, it runs unfortunately with a lower efficiency and produces a $\mathrm{kWh}$ at a higher cost [3].

Another problem is linked to the over-specialisation of the economy that forces to install often an over-sized energy capacity to cover factors such as a high seasonal demand.

Then, in an island grid, the electricity generation is heavily dependent on diesel engines, expensive and polluting but appropriate according to their small unit size and the relative starting-speed and ramp rate.

\section{Overview of the electrical energy situation}

As previously underlined, diesel engines are the most adapted electricity sources for the islands. The high contribution of fuel in the electricity production in French islands is presented in Figs 3 and 4 for 2016.

The fuel facilities (diesel engines using heavy or sometimes light fuel) and the combustion turbines (light fuel) represent between $40.6 \%$ (Corsica) to $99.93 \%$ ( $\mathrm{St}$ Barthelemy) with sometimes a non-negligible part of power plants using coal and bagasse. The electrical energy produced by fuel varies from $27.3 \%$ (Reunion, but $47 \%$ from bagasse-coal) to $100 \%$ for St Barthelemy. It was impossible to separate the coal production from the bagasse production because the data were not available what it is a problem because coal belongs to fossil fuel and bagasse to the RE fuel.

Fig 5 illustrates the distribution in installed power (a) and in produced energy for the French island and for France. These distributions of the energy means differ widely compared to the French mainland situation [6]. 


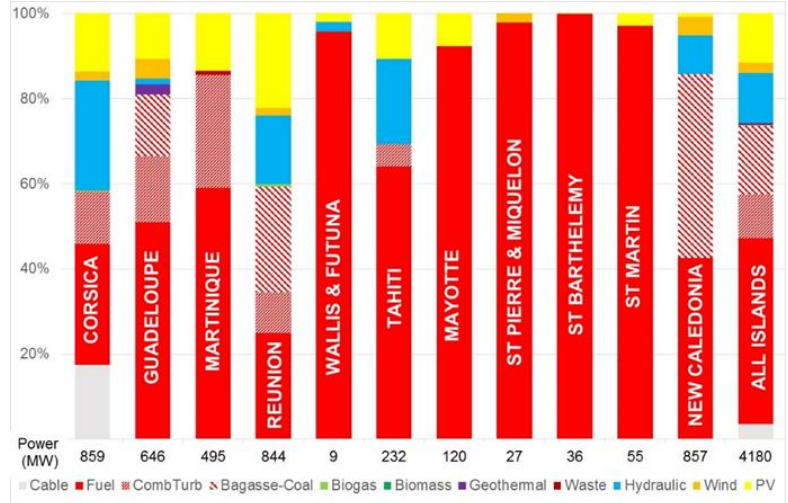

Adding peak power of fossil generators (guaranteed power) and of intermittent renewable systems (stochastic power) can be discussed.

Fig 3. Repartition of installed powers in the islands for 2016

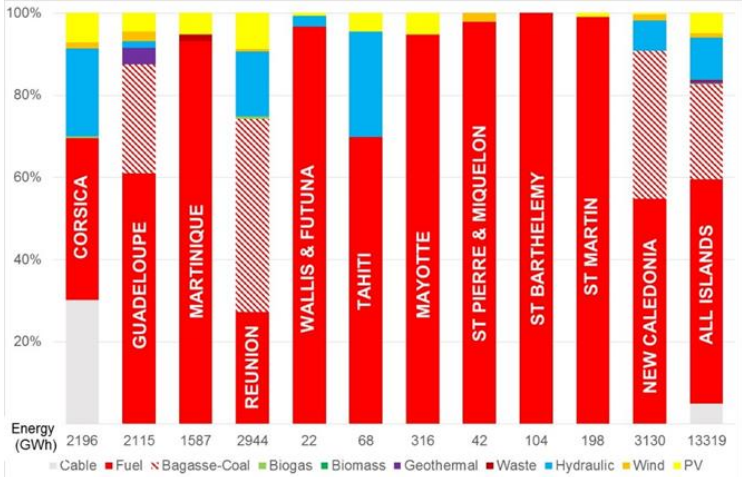

Bagasse: pulp after the extraction of juice from sugar cane used as fuel.

Fig 4. Repartition in produced energy in the islands for 2016
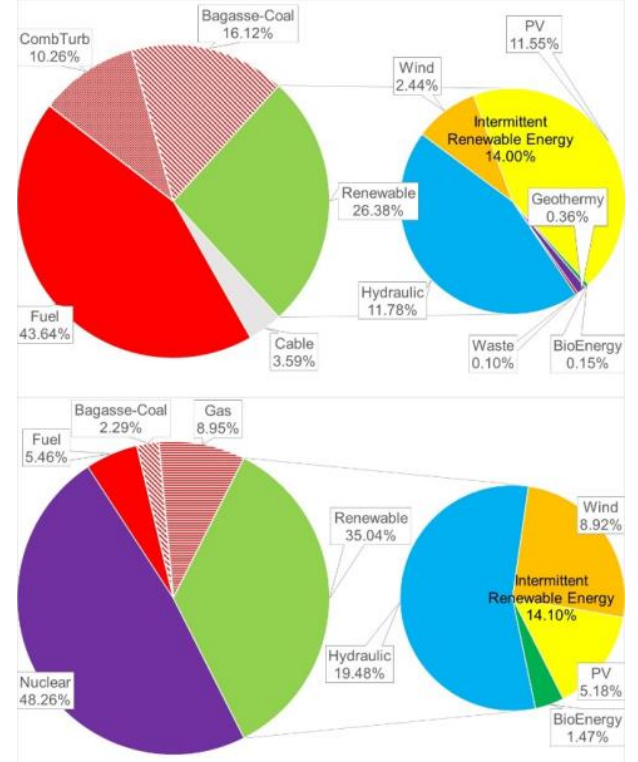

a) Repartition in installed peak power for the French islands (left) and France (right) in 2016.

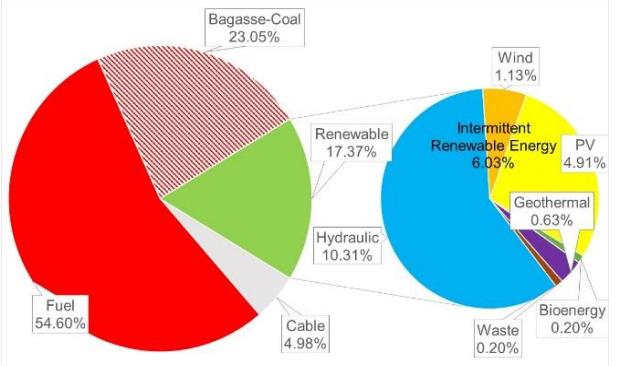

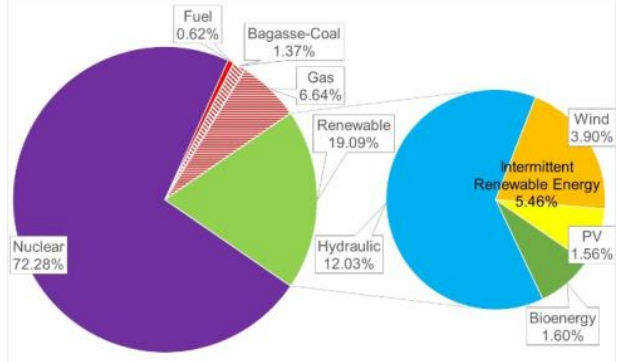

b) Repartition in produced energy for the French islands (left) and France (right) in 2016.

Fig. 5. Comparison of the electrical energy situation for the French island and for France a) in installed power b) in produced energy.

The share of RE in the total production is about $17.37 \%$ in 2016 against $19.09 \%$ for the French mainland but the part of the intermittent RE sources is more important in islands. France has a high hydraulic potential that it is rarely present in the islands. Moreover, we note that the part of $\mathrm{PV}$ energy is more important than wind energy in islands $(80 \% \mathrm{PV} / 20 \% \mathrm{Wind})$ while the reverse is true in France $(30 \% \quad \mathrm{PV} / 70 \%$ Wind), probably due to the difficulty to install large wind turbines in small territories for technical, environmental and visual reasons. The French electrical situation is very particular because more than $72 \%$ of the electrical energy is produced by nuclear power plants.

The total installed RE power in 2015 for the 5 territories was about $1200 \mathrm{MW}$ and has risen by $42 \%$ since 2010 . This increase is mainly due to photovoltaics ( +292.5 MWp since 2010) and to the Rizzanese hydraulic plant (55 MW) in Corsica (Fig. 6).

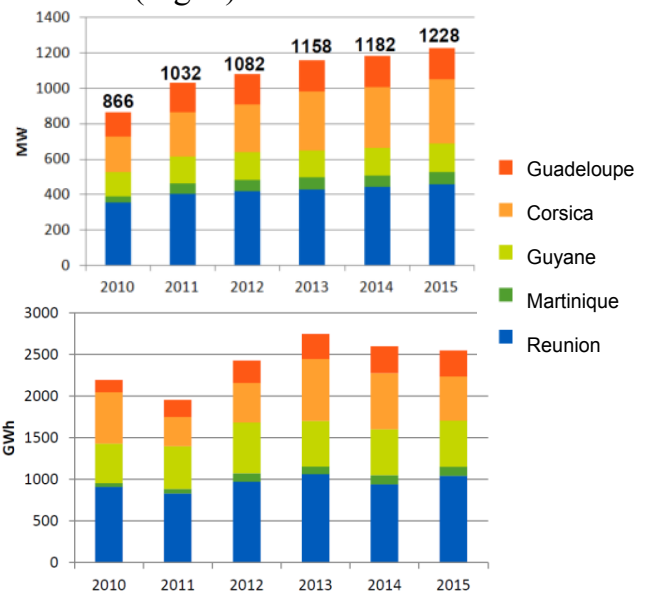

Fig. 6. Evolution of the RE power and production [7].

\section{Legal and financial aspects}

In Corsica and in the overseas departments, the cost of electricity is, in the best-case scenario, equal to at least twice that of the selling price of electricity secured by the electricity tariff balancing out in all the French territory.

The European Union defined a special status for the "small isolated networks" for which the states members can adopt specific measures different from the European continent [8]. The French law [9] identifies some "area 
no-interconnected to the continental network" called ZNI (Zones Non Interconnectées): The French Overseas Communities and Departments must produce in totality their electricity (not interconnected) and largely in Corsica (partially connected).

The French laws impose [9-11] an equalization of electricity tariff over all the French Territory and took in place the Contribution of the Public Service of Electricity (CPSE) which is paid by all the electricity consumers and serves particularly to compensate the high gap in insular area between the production cost and the regulated selling price of electricity. This CPSE is controlled and attributed by an Energy Regulatory Commission (CRE). Moreover, the purchasing obligation has been implemented by the law of February 2000 [9] and EDF is obliged to conclude some electricity purchasing agreements if the independent producers. The CSPE contributes also to compensate the over cost due to this purchasing obligation.

Until 2010, it is the geographical tariff equalization that generated the highest part in the CSPE. From 2011, the "RE part" took the first place (60\% in 2013) mainly due to the development of PV and to a lesser extend of wind energy. For 2015, the total amount for the CSPE was 6.3 $\mathrm{G} €$ with $1.3 \mathrm{G} €$ for the tariff equalization in the noninterconnected areas [12-13]. The CSPE in 2015 represented $19.5 € / \mathrm{MWh}(+3 € / \mathrm{MWh}$ compared with 2014); the repartition of the CSPE in 2015 and its evolutions since 2003 is shown in Fig 7. Since 2003, the CSPE for the geographical tariff equalization are increasing by about $15 \%$ per year.

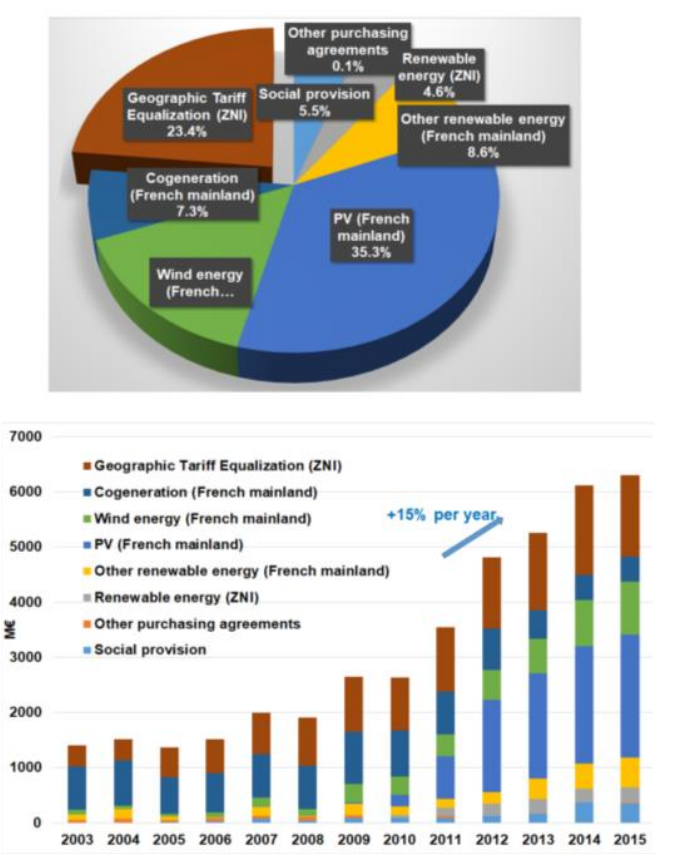

Fig. 7. Repartition of the CSPE amount in 2015 for a total of 6.3 $\mathrm{G} €$ and annual evolution [13].

According to the French Energy Regulation Commission (CRE), in 2010, the produced MWh cost was between 122 and $315 €$ for a regulated selling price at 51.7 $€ / \mathrm{MWh}$ [13]. In 2013, the electrical MWh cost price is around $225 € / \mathrm{MWh}$ i.e. between 4.5 and 5 times more expensive. The average cost per island depends on the characteristics of the production system. In 2013, it was $206 € / \mathrm{MWh}$ in La Reunion, $172 € / \mathrm{MWh}$ in Corsica, 259 $€ / \mathrm{MWh}$ in Martinique, $243 € / \mathrm{MWh}$ in Guyana e 247 $€ / M W h$ in Guadeloupe [14]. The evolution of the cost price for ZNI and the average cost per island are shown in Fig. 8 [14].

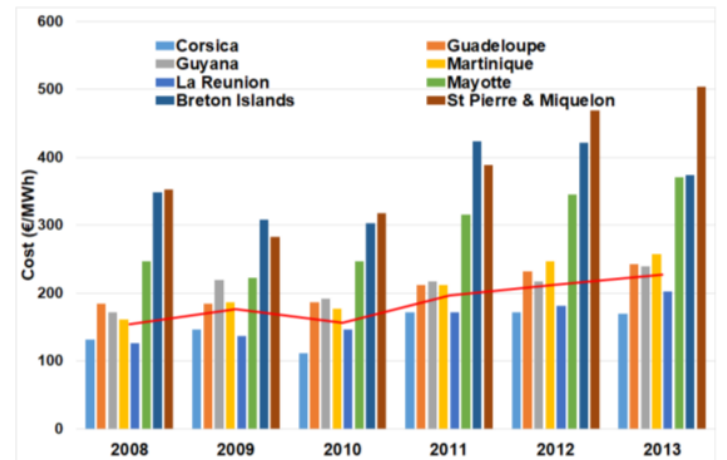

Fig. 8. Average cost in ZNI and for each island from 2008 to 2013 [14].

For these costs, some hypothesis were taken: its depends on the frequency of utilization of the combustion turbine (used for peak shaving and producing a $\mathrm{kWh}$ at a high price) and on the runoff, the increase of the electricity demand, exceptional events such as strikes, technical unavailability, ... The average cost for the French islands by energy production mean is shown in Fig. 9.

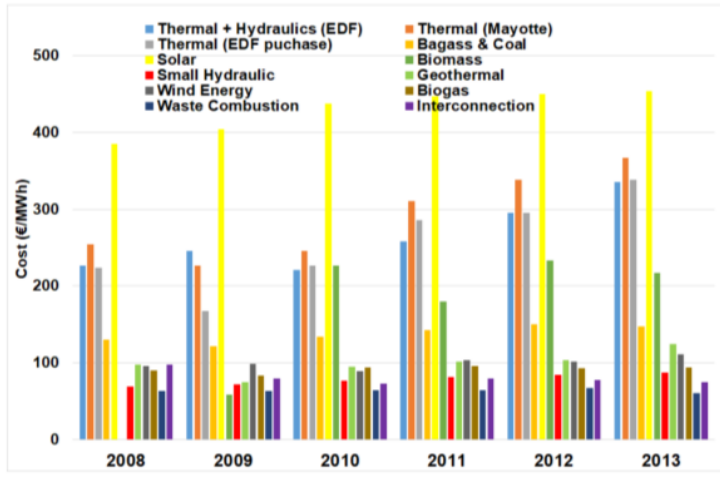

Fig. 9. Production costs by production means [14]

It is unfortunately impossible to find production costs distinguishing combustion turbine (very costly and using light fuel) and thermal motor (using heavy or light fuels). The PV production is the most expensive with 450 $€ / M W h$ in 2013 , the electricity production by fuel follows. The production cost by bagasse and coal is relatively constant on the period 2008-2013 (between 120 and $150 € / \mathrm{MWh})$. The waste combustion, small hydraulic, geothermal energy and wind energy are the most competitive but their development is relatively limited.

The high cost for the PV production is a consequence of the high purchase price introduced until 2010. Actually, the cost presented here is not the production cost but the purchase cost by EDF of the PV kWh produced by a private company or an individual citizen. In view to boost the development of the PV systems in France, and particularly in the islands (before 2005 with a special price for Corsica and overseas departments), high purchase costs were imposed by the French government. 
The feed-in tariffs for RE electricity are applied on a contractual period given for each RE [15]. The principles of purchase obligation are fixed by the law $n^{\circ} 2000-108$ of the February 10, 2000 [9]. Some regular calls of tender are launched and some private agreements are signed on the basis of the methodology written by the Energy Regulatory Commission (CRE).

Fig. 10 shows the price evolution in France between 2002 and 2017; in 2010, due to a "too rapid" development of the PV systems in the French territory (due to a high purchase cost), a moratorium on the PV installation was decided by the French government; after this moratorium, the PV $\mathrm{kWh}$ price decreased.

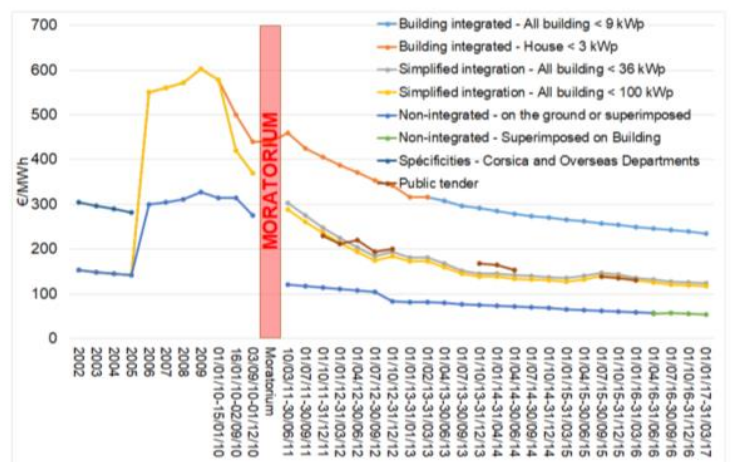

Fig. 10. Evolution of the purchase cost (by EDF) of the PV $\mathrm{kWh}$ produced [16].

\section{The Corsican case}

\subsection{Brief presentation}

With its $8680 \mathrm{~km}^{2}$ and an average altitude of 568 meters, Corsica is the smallest, but the most mountainous of the three big occidental Mediterranean islands (Fig. 11). The island is $183 \mathrm{~km}$ long from $41^{\circ} 19^{\prime}$ to $43^{\circ}$ north, and 83.5 $\mathrm{km}$ large from $6^{\circ} 31^{\prime}$ to $7^{\circ} 13$ east.

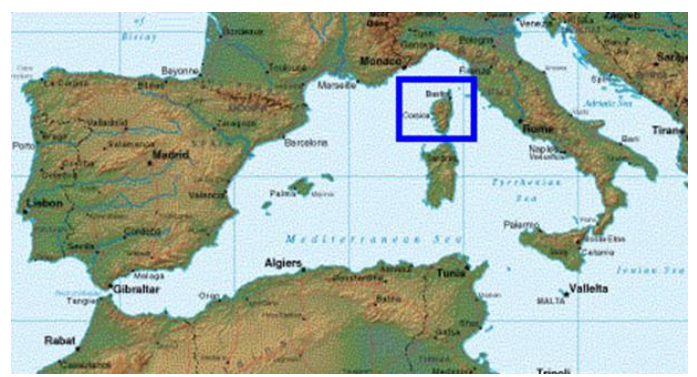

Fig. 11. Position of the Corsica Island in the occidental Mediterranean sea.

Mediterranean by its situation, Corsica is alpine by its structure. The central fold, of North-Northeast direction, South-Southeast direction which splits Corsica into 2 parts, forms an important barrier which can be crossed over by passes often situated at a height of more than $1,000 \mathrm{~m}$ and, with snow in winter; 10 mountains exceed $2,000 \mathrm{~m}$. Corsica has more than $1,000 \mathrm{~km}$ of coastal area (14\% of the total French coasts).

With about 324,212 inhabitants in $2014,+1.2 \%$ per year, Corsica has an average population density equal to 37.4 inhabitants $/ \mathrm{km}^{2}$, the lowest of France (compared with 104.2 inhab $/ \mathrm{km}^{2}$ in France). But in rural areas, this density falls down to $7-10$ inhabitants $/ \mathrm{km}^{2}$. $44 \%$ of the population live in district of less than $100 \mathrm{inhab} / \mathrm{km}^{2}$.

Moreover, Corsican culture is mainly pastoral and a lot of sheepfolds are scattered all over Corsican country side. It is the only island of the Mediterranean sea which has not found the population it had at the beginning of the $\mathrm{XX}^{\text {th }}$ century. It is three times less populated than Balearics, six time less than Sardinia and twenty times less than Sicily. The increase of the population is moderated and mainly due to migrations. Two-thirds of the population live in coastal areas as and this is expected to rise up three-quarters by 2030 .

During the summer, the island has more than 1.3 million inhabitants ( $60 \%$ of the tourism is in July-August), there are about 3 million tourists per year for 35 million occupied beds. This parameter is important for the energy production of the island.

Total employment in Corsica is about 122,400 persons in 2015 , the local economy is unbalanced: the tertiary sector represents $82.4 \%$ of jobs, industry $5.7 \%$ (the least industrial area in France), agriculture $1.5 \%$ and construction $10.6 \%$. It is an economy where there is a very high level of seasonal employment. The GDP per capita (The Gross Domestic Product) is the lowest in France $(26,432 €$ in 2014 against $32,736 €$ for France i.e $19 \%$ inferior to the French average).

\subsection{Energy situation}

The insularity induces a high dependence for energy supply. Thus, even if the part of RE in the energy mix is important, the island is dependent on exterior supply for about $87 \%$ of the total primary energy in 2014 (fuel for transport, LPG for heating, fuel for electrical production, high electrical importation from Italy and Sardinia, ...).

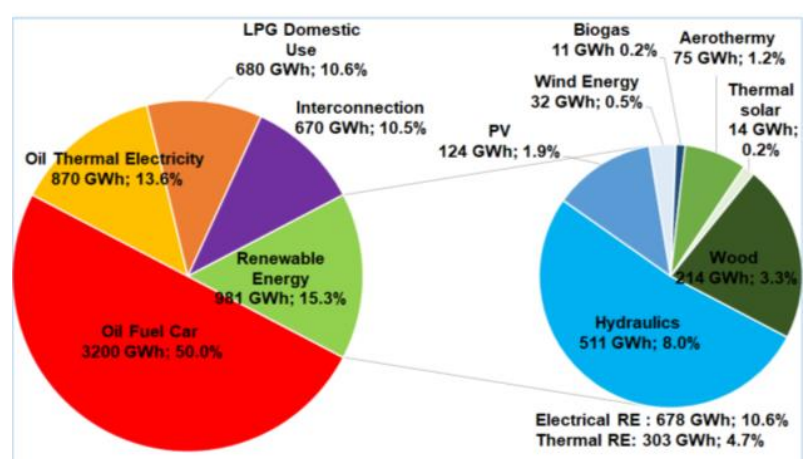

Fig. 12. Balance of final energy consumption in GWh (2014)

The balance for 2014 (Fig. 12) without climatic correction in final energy is $6430 \mathrm{GWh}$ (550 ktoe); the $\mathrm{RE}$ in this balance represents about $16 \%$ of the final consumption.

In 2005, the Corsican Assembly (deliberative body of the Collectivity of Corsica) decided an energy plan for 2005-2025. The objectives were to obtain a tripartite repartition between:

- RE (mainly hydroelectricity 27\%) and PV (6\%) and wind energy;

- Thermal productions units

- Electricity importation from Italy (SACOI cable) and Sardinia (SARCO cable). 
The electrical system for Corsica in the end of 2016 is shown in Fig. 13; Corsica is partially connected to the Italian mainland by two cables a DC one (SACOI 50 $\mathrm{MW}$ ) and a $\mathrm{AC}$ one (SARCO: $10 \mathrm{MW}$ ). Islands are rarely connected to mainland that makes Corsica particularly interesting from an electrical point of view.

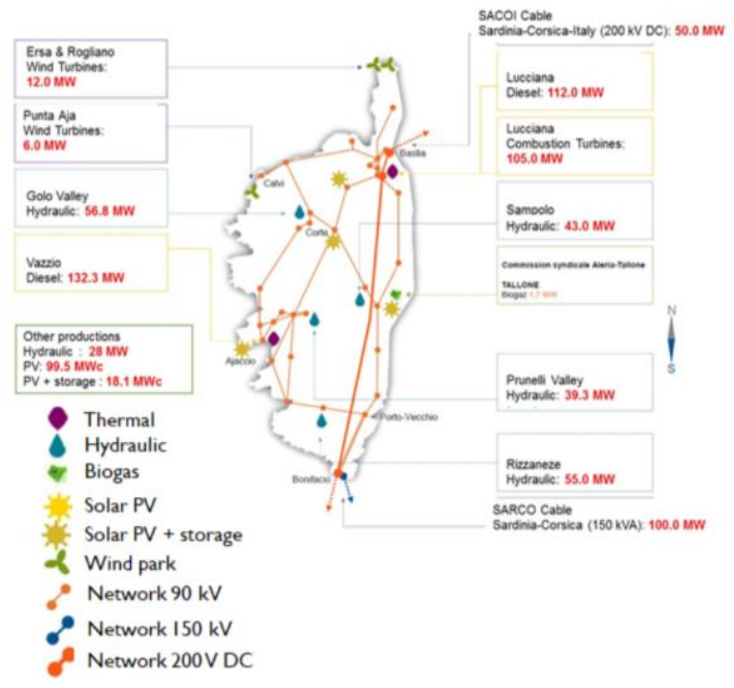

Fig. 13. Electrical system in Corsica in the end of 2016.

New production means were realized during the last years:

- The investments were multiplied by 2 for the electrical network in view to improve the quality of the electricity;

- The power of the SARCO cable put into service in 2006 reached $100 \mathrm{MW}$ in 2010;

- A new $40 \mathrm{MW}$ combustion turbine (light fuel for peak shaving) in 2008;

- A new 55 MW hydraulic plant in Rizzanese in 2013.

- A new thermal power plant (Lucciana B) using light fuel in 2014.

The evolution of the electrical system in Corsica is shown in Table 2. In 2016, the RE is $30.5 \%$ of the distributed electrical energy. The total energy produced in 2016 is $2196 \mathrm{GWh}$, the maximum power was 461 MW. The electricity demand in Corsica is very sensitive to climatic variations: about $37 \%$ of the consumption depends on the climate (temperature, nebulosity ...) for heating (24\%) and cooling (13\%). The electrical losses, difference between produced energy and distributed energy was equal to $270 \mathrm{GWh}$, i.e. $12.3 \%$.

The Corsican consumption depends on the season. The consumption is higher in winter due to the electrical heating. In summer, the cooling and the increase of the population due to the tourism conduce slightly to a lower consumption. The consumption is minimal in autumn and spring. The load profile was plotted in Fig. 14 for about two years.

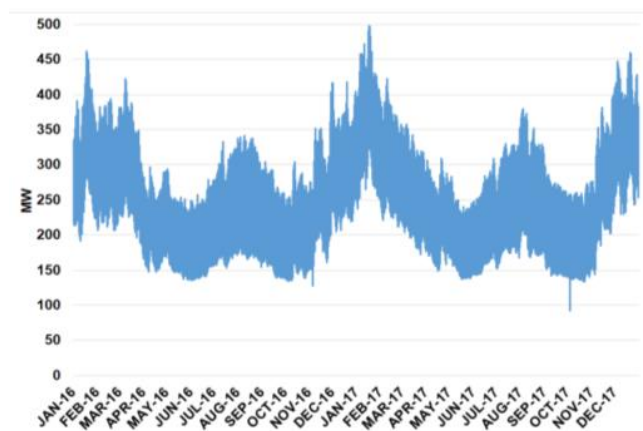

Fig.14. Evolution of the electrical consumption (hourly data) in MW for 2016 and 2017 [17]

Table 2. Power of the electrical system in 2005 and 2015.

\begin{tabular}{|c|c|c|c|c|c|c|}
\hline \multicolumn{4}{|c|}{2005} & \multicolumn{3}{|c|}{2015} \\
\hline Type & Site & Power & Total & Site & Power & Total \\
\hline \multirow[b]{2}{*}{$\stackrel{\bar{E}}{\stackrel{E}{E}}$} & Lucciana & 77 & & Lucciana & 112 & \multirow[b]{2}{*}{$\begin{array}{c}244 \\
(+35)\end{array}$} \\
\hline & Vazzio & 132 & 209 & Vazzio & 132 & \\
\hline \multirow[b]{2}{*}{ ठํㅠ } & Lucciana & 65 & \multirow[b]{2}{*}{65} & Lucciana & 105 & \multirow{2}{*}{$\begin{array}{c}105 \\
(+40)\end{array}$} \\
\hline & Vazzio & 0 & & Vazzio & 0 & \\
\hline \multirow[b]{2}{*}{ हैं कै } & SACOI & 50 & \multirow[b]{2}{*}{50} & SACOI & 50 & \multirow{2}{*}{$\begin{array}{c}150 \\
(+100)\end{array}$} \\
\hline & SARCO & 0 & & SARCO & 100 & \\
\hline \multirow{6}{*}{ 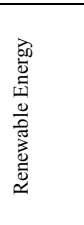 } & Hydro & 139 & \multirow{5}{*}{160} & Hydro & 194 & \multirow{6}{*}{$\begin{array}{c}342 \\
(+182)\end{array}$} \\
\hline & Small H & 21 & & Small H & 26 & \\
\hline & Wind & 0 & & Wind & 18 & \\
\hline & PV & 0 & & PV & 97 & \\
\hline & $\begin{array}{l}\text { PV } \\
\text { storage }\end{array}$ & 0 & & $\begin{array}{l}\text { PV } \\
\text { storage }\end{array}$ & 5 & \\
\hline & Biogas & 0 & & Biogas & 2 & \\
\hline
\end{tabular}

Five typical electrical load profiles are plotted in Fig. 15:

- The day with the maximum consumed power;

- The day with the minimum consumption (useful for estimating the disconnection of intermittent RE systems due to the $30 \%$ limitation);

- One average day profile by season: winter, summer and Autumn-Spring.

The difference between the smaller and higher consumed power is important and the low consumption during some periods will have some consequences on the disconnection of intermittent RE plants. The annual electrical energy mix in 2016 is presented in Fig. 15. The repartition (for 2016) is about $1 / 3$ for thermal energy (diesel), 1/3 for interconnection and $1 / 3$ for $R E$, it confirms the objective to have an energy tripod and progressively to increase the RE part.

Fig. 16 illustrates the energy means staking for a characteristic winter and summer day and for the day with the minimum consumption. The average MWh cost per hour was also plotted [17]. It appears that during summer the water resource is not used (generally, kept for drinkable water or agriculture utilization). The combustion turbines are used to shave the consumption electrical peak. The $\mathrm{kWh}$ cost varies greatly according to the repartition of the electrical production types, with a maximum when the costly combustion turbines are used and a minimum cost when hydraulic production is used (winter). 


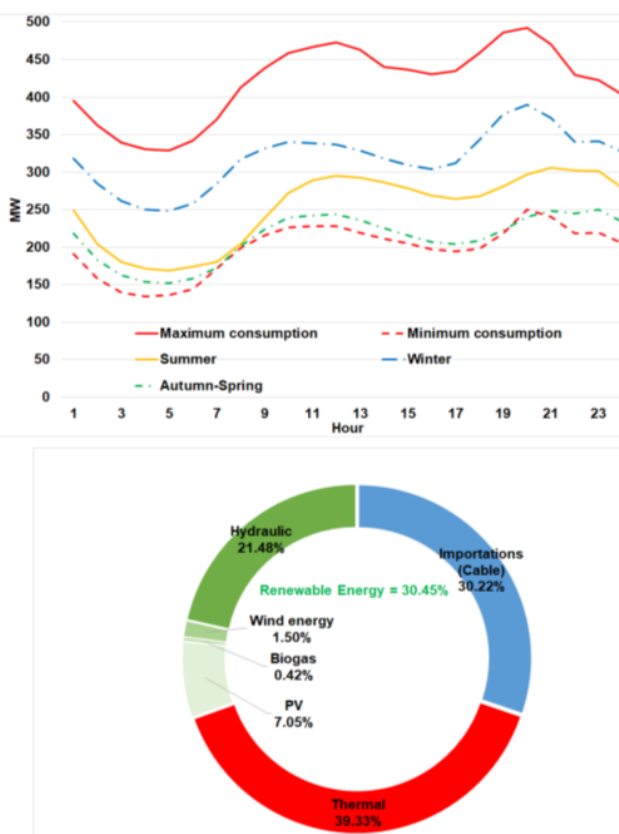

Fig. 15. The five typical load profiles for Corsica and the electrical mix in 2016 [17].

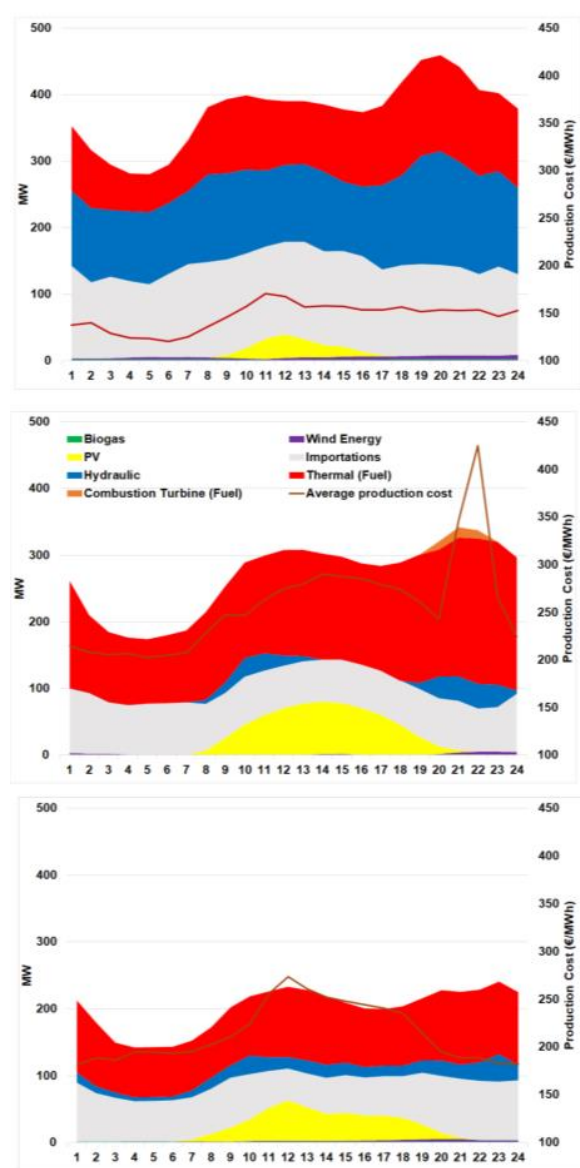

Fig. 16. Energy means stacking for winter (18/01/2016), summer (09/08/2016) and for the day with minimum consumption $(11 / 06 / 2016-$ minimum $=128 \mathrm{MW})$ [17]

Due to the small power consumption in some periods (mainly May and June, after the heating period and before the arrival of tourists) and the limitation at $30 \%$ of the intermittent power on the grid at a given instant, some disconnections of PV systems occur. Fig 17 shows the monthly number of disconnections in 2016 for a total number of 54 hours and a loss of PV energy produced equal to $577 \mathrm{MWh}$ i.e. $0.4 \%$ of the total PV production in 2016. As an example, the electrical production of the 27 May is shown in Fig 18, the limit of 30\% of the total production has been reached and some PV systems were disconnected to the grid.

In winter, the thermal production is directly linked to the runoff and the temperature. It can have a high variability from year to year. In summer, thanks to the hydraulic and photovoltaic, a slight increase of the production of the diesel energy means allows to shave the consumption peak. But, for the evening peak consumption, higher, all the available diesel engine were started on and a combustion turbine was worked.

The security of the Corsican electrical grid must prevent a loss of an energy means due to an unpredictable event. Then, the loss of the SARCO cable can imply the loss of the wind and photovoltaic energy and of the DC/AC conversion station for the SACOI cable.

The security can be guaranteed and efficient only if the sum of electrical powers injected on the network at each moment by: RE, SARCO and SACOI does not exceed a given limit of the total instantaneous load; this rule explains the variations of the imported power for the winter day.

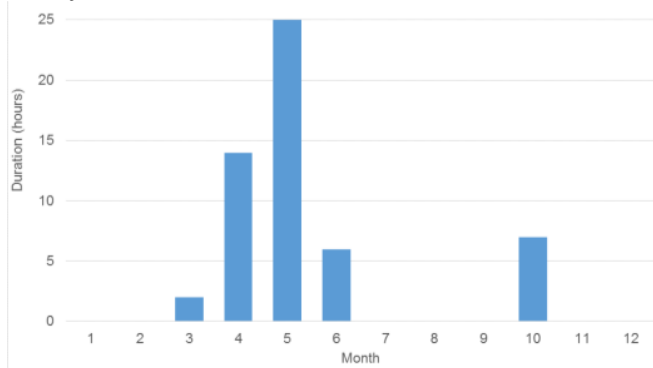

Fig. 17. Number of PV systems disconnections in 2016 [17].

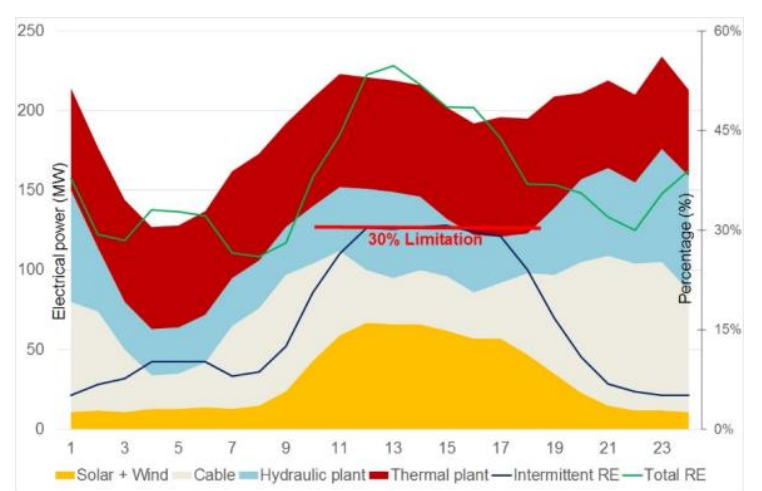

Fig. 18. Disconnection of PV systems due to the limitation at $30 \%(27 / 05 / 2014)$

The monthly energy mix is presented in Fig. 19 for 2016. During summer, the hydraulic production is limited (decrease of the water potential and utilization of the dams for drinking water) and the diesel production is maximum.

The production cost in Corsica from 2008 to 2013 is presented in Fig. 20 [18]. The small hydraulic produces electricity with the lower cost, followed by importation, biogas and wind energy. The data obtained by the Energy Regulation Commission does not allow to distinguish the costs for hydraulic and thermal plants. The high cost for $\mathrm{PV}$ production $(450 € / \mathrm{kWh})$ is a 
consequence of the high purchase price introduced until 2010.

The energy bought via the two cables SACOI and SARCO are very competitive and allows for Corsica to have a competitive price compared with the other ZNI.

The installed wind energy peak power has not increased since 2000 with $18 \mathrm{MW}$, but the total installed PV peak power has increased very rapidly and reaches more than 140 MW today.

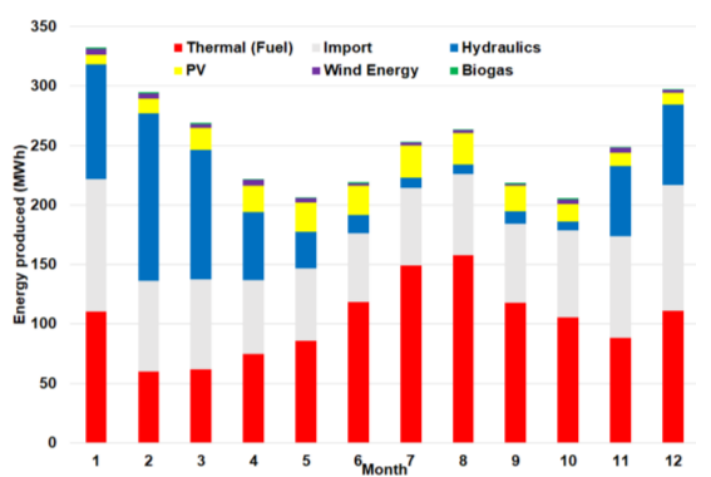

Fig. 19. Electrical energy mix month by month in Corsica (EDF data, 2017).

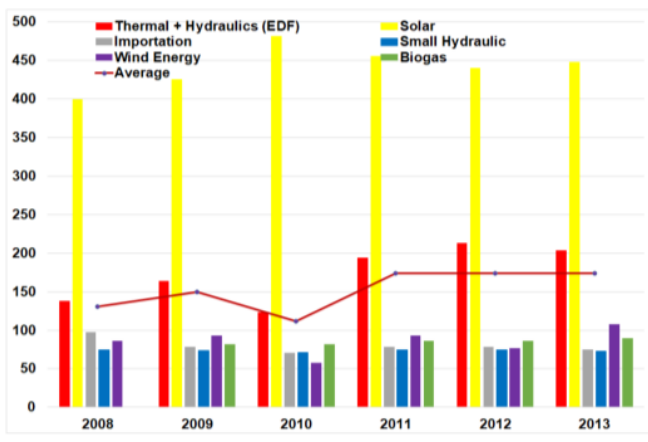

Fig. 20. Production and purchase cost (2008-2013) [18]

\subsection{Expected future}

The long-term energy plan called PPE (Pluriannual Planning for Energy) is a management tool for the energy policy created by the decree $n^{\circ} 2015-992$ on the energy transition for the green growth [19]. It concerns the French metropolis and the non-interconnected area (ZNI). The PPE for the French metropolis is elaborated by the French government and for the ZNI are coelaborated with the local authorities. This PPE covers two periods: 2016-2018/2019-2023. For Corsica, the PPE decree was published on 2015, 18 December [18], the main part of the information given in this paragraph comes from this decree. The main objectives are:

1. for electrical production:

- to increase the installed power of the RE in the electrical production;

- to increase the production of heat and cold by RE by 130 GWh in 2023 (compared to 2015).

2. for increasing the supply security:

- to increase the disconnection threshold for intermittent RE to $35 \%$ in 2018 and $45 \%$ in 2023 ;

- to realize a gas supply infrastructure to supply the thermal electrical plants;
- to implement a new $250 \mathrm{MW}$ combined cycle power plant using domestic fuel oil (until the gas supply);

- to convert the thermal energy means in gas ones;

- to renew the DC cable and to increase its power to $100 \mathrm{MW}$.

3. for increasing the energy efficiency and decreasing the fossil fuel consumption:

- to develop $700 \mathrm{PV}$ electrical charge ports for electrical vehicles:

- to reduce the energy consumption of $400 \mathrm{GWh}$ until 2023.

4. concerning new infrastructures:

- to develop new hydraulic power plants

- to implement a hydro-pumping plant in an existing station.

\section{Discussion}

It may seem a contradiction: managing an electrical grid in islands is more complex than in inland for all the reasons previously exposed and even more when "intermittent and stochastic" RE systems are integrated in this grid; despite this, in these areas the rate of "fatal" RE (i.e. without hydraulic and biomass energy) in the total production is higher than in the French mainland territory.

This strong interest for fatal RE systems in the islands is mainly due to the high energy production cost. The utilisation of costly fossil fuels due to the fluctuations in crude oil prices, the small size of the production means and a more expensive maintenance due to the remoteness cause such high costs and encourage the emergence of innovating solutions as the development of RE and the setting up of a policy of electricity demand reduction and energy management.

The islands have everything to gain by developing the use of RE from an economic point of view but also for ecological reasons.

A very good example is given by the development of an hybrid PV/wind/battery system in the island of Tilos in the frame of a Horizon 2020 program [20].

In view to delete or to decrease the constraint due to the integration limits, three solutions must be developed:

- To predict the production of fatal RE sources in view to achieve by anticipation an optimal switchover towards conventional electricity plants in keeping in mind that the starting of a conventional system requires a long time; the prediction of these productions is generally less accurate in an insular networks;

- To develop smart grids for the transport and the management of the production means. The network will be managed with more flexibility for reaching the production/demand balance in controlling both the production and the consumption;

- To develop energy storage means in order to absorb the surplus energy and to release it when the consumption requires. Several energy storage means were studied for islands.

The objectives of this paper are not to develop more the three interdependent solutions but to show that insular territories are well adapted to implement and to test these 
solutions before being extended to any other parts of the World. Moreover, the electricity companies that manage electricity in the islands acquired a good experience and reached a high level of knowledge because they have been facing this challenge for a long time.

In each island an adapted politic on energy-saving and development of efficient and/or RE systems for heat production is implemented and participates to the reduction of the electrical consumption.

\section{Conclusion}

The integration and development of RE in the insular territories are in progress and often reached a higher level than in French mainland.

Several specific problems were underlined for the islands:

- the need for low power electrical systems with rapid starting, very costly and almost always using fuel;

- the presence of high energy losses in the electrical grid increasing again the electricity cost;

- a high number of electrical failures and shedding;

- and consequently, an electrical kWh cost very high, 3 to 4 times higher than in mainland.

These specific aspects and constraints have enabled the insular electrical operators to develop for a long time a higher experience in the network managing.

The higher cost of electricity production pushes islands to use their natural resources in view to reach energy independence, to reduce their fuel dependence and to preserve their environment.

The share of randomness RE is higher in French insular territories than in mainland France because in these areas these energies reach the break-even point more easily, and particularly compared with the cost of the electricity produced by fuel.

In Corsica, there is a strong will to continue the RE development. The continuity of this development will not be accomplished without the development of efficient prediction of the energy production, without the development of energy storage means and without an optimal management of the energy flux via the utilization of smart grids.

The islands are becoming RE development laboratories and probably the islands maps the road for the future of the energy supply in the World

\section{Acknowledgement}

This work is supported by European Union's Horizon 2020 research and innovation programme under grant agreement No 646529 through the TILOS project (Technology innovation for the Local Scale, Optimum integration of Battery Energy Storage).

\section{References}

1. EDF. Technical reference: Key parameters for the insular electrical systems safety. SEI REF 05, Technical report, (2008).

2. EDF. Intermittent random renewable energy in the insular energy system: why a maximum integration rate of $30 \%$, EDF report, 19/05/2009, CCP SEI (2014)

3. D. Marin, pHd Dissertation, Ecole Centrale de Lille (2009).

4. Y. Barlier, Proc. Dissemination of the advanced control technologies and SCADA systems for the isolated power networks with increased use of renewable energies, Ajaccio, (2000).

5. J. Lacoste, IEEE P\&ES, RTE, La Défense, Paris (2013).

6. RTE, RTE Report2016. www.rte-france.com.

7. EDF SEI. Bilan électrique EDF SEI 2016. EDF report, July 2017 (in French).

8. European Union. Directive 2003/54/EC. Official J. European Union, L176-37-L176-55, 15/01/2003.

9. Legislative French Assembly. French Act 2000-108 $(10 / 02 / 2000)$ reinforced on 01 January 2012. (In French).

10. Legislative French Assembly. French Act SPEGEEG $\mathrm{n}^{\circ} 2004-803$ of August 9, 2004 reinforced the 01 January 2013. (In French).

11. Legislative French Assembly. Energy Program Act POPE $\mathrm{n}^{\circ} 2005-781$ of 13 July 2005 reinforced the 01/06/2011. (In French).

12. C. Crampes, T.O. Léautier. La Tribune journal, 27/05/2015. www.latribune.fr.

13. Commission de Régulation de l'Energie (CRE). Montant et évolution de la CSPE. 2017. www.cre.fr.

14. CRE. La contribution au service public de l'électricité (CSPE) : mécanisme, historique et prospective. October 2014. www.cre.fr.

15. EDF, the renewable energies in Corsica and in overseas: detailed panorama for the 1st January 2016, EDF report, 2017 (in French).

16. Hespul association, photovoltaique.info website, http://www.photovoltaique.info/, 2018.

17. EDF. Open-data Corsica and Overseas, https://opendata-corse-outremer.edf.fr/, 2018.

18. Multiannual programming of Energy for Corsica. French Decree $n^{\circ} 2015-1697$. 18/12/2015 (in French).

19. Multiannual programming of Energy for Corsica. French Decree n²015-992. 17/08/2015 (in French).

20. K. Kaousias, T.Xygkis, G.Papoutsis, E. Stavropoulou, T. Patsaka, C. Kourelis, Z. Mantas, J. Kaldellis, C. Pronios, T. Delaplagne, G. Notton, M. Todeschini, D.H. Alamo. The European Research Project "TILOS". CiGRE Session, Palais des Congrès, Paris. 26-31/08/2018. 